\title{
Construção de Portfólios de Matemática usando Pbworks
}

\author{
Aline Silva De Bona - PPGENSIMAT-IM-UFRGS - vivaexatas@yahoo.com.br \\ Marcus Vinicius de Azevedo Basso - PPGENSIMAT-IM-UFRGS - mbasso@ufrgs.br
}

\section{Resumo}

O trabalho é parte de uma prática docente baseada na autonomia do estudante via construção de portfólios de matemática, valendo-se de estratégias metacognitivas construídas pelos estudantes e pelo encantamento destes com as tecnologias digitais. $\mathrm{O}$ pbworks é um espaço free na internet onde os estudantes utilizam como caderno online, pois neste espaço podem-se postar todas as atividades da aula de matemática de forma a explorar a criatividade e o aprendizado de cada estudante. Este espaço tem a mesma finalidade do portfólio de matemática que é mobilizar os estudantes a aprenderam matemática, assim podendo ser o portfólio de matemática o próprio ou nele estar postado, mas com o foco no recurso, ou seja, qual recurso tecnológico digital viabilizaria ainda maior necessidade de se aprender a matemática da escola? Os objetivos desse trabalho é agregar as aulas de matemática cada vez mais às tecnologias digitais por ser um recurso facilitador na aprendizagem de matemática segundo as solicitações dos estudantes, em função da sua dinamicidade e interatividade, que viabiliza a correção do erro como aprendizagem. O trabalho é desenvolvido pelos estudantes do $3^{\circ}$ ano do Ensino Médio, de uma escola pública estadual de Porto Alegre, com uma metodologia de pesquisa-ação, que une a ação e a pesquisa, devido ao fato dos estudantes serem nativos digitais esses ajudam a professora com o uso da tecnologia e a professora aos estudantes desperta o interesse pelo estudo da matemática; ser $95 \%$ extraclasse e a comunicação é prioritariamente online. Os resultados indicam o envolvimento dos estudantes nas aulas de matemática, além do brilho no olhar de cada estudante olhando seu próprio trabalho se sentido capaz e entusiasmado para aprender mais e mais matemática.

Palavras-Chaves: Tecnologias Digitais, Educação Matemática, Portfólio de Matemática.

\begin{abstract}
The work is part of a teaching practice based on the autonomy of the student via the construction of portfolios in mathematics, making use of metacognitive strategies constructed by students and the enchantment with these digital technologies. The pbworks is a free space on the internet where as students use online notebook, because this space can be posting all the activities of a mathematics class in order to explore creativity and learning of each student. This space has the same purpose of portfolio mathematics that is to mobilize students to learn mathematics, and so could be the portfolio of mathematics itself or of it being posted, but with the focus on action, ie, which feature digital technology would allow even greater need to learn math in school? The objectives of this work is to add the math classes increasingly to digital technologies to be a resource facilitator in the learning of mathematics according to the requests of the students, depending on the dynamics and interactivity, which enables the error correction and learning. The work is developed by students in the 3rd year of high school, a public school in Porto Alegre, with a methodology of action research, which combines action and research due to the fact that students are digital natives they help the teacher with the use of technology to students and the teacher arouses interest in the study of mathematics is $95 \%$ and extracurricular communication is primarily online.
\end{abstract}


The results are of great involvement of students in math classes, beyond the shining eyes looking at each student's own work felt able and enthusiastic to learn more and more math.

Key-Words: Digital Technologies, Mathematics Education, Portfolio of Mathematics.

\section{Introdução}

Em função do envolvimento dos estudantes com o trabalho desenvolvido sobre os portfólios de matemática em 2009, e dos inúmeros apontamentos dos mesmos sobre o quanto a tecnologia é importante e facilitadora na aprendizagem de matemática, segundo Bona e Basso (2009a; 2010), em 2010, incorporou-se a esta prática docente o uso do espaço free denominado pbworks. O objetivo foi o de proporcionar ao estudante mais um espaço de aprendizagem dinâmico e interativo, além da sala de aula com a professora, com os colegas da sua turma, de outras turmas, e amigos, por exemplo. Este espaço possibilita a correção do erro como parte do processo de aprendizagem de forma "lúdica" ao estudante, na medida em que ele corrige suas questões erradas ou incompletas, aponta o erro do colega de forma natural e constrói estratégias novas de resolução.

Os portfólios de matemática são os próprios pbworks ou nele estão postados, porque alguns estudantes entendem o pbworks como caderno de aula digital. Assim, eles podem postar todas as atividades e trabalhos solicitados, não somente pela professora de matemática, mas também de literatura como é o caso dos trabalhos publicados nessa disciplina, a pedido dos próprios estudantes. No portfólio de matemática produzido de forma não-digital há uma escolha das atividades que serão postadas para evidenciar o aprendizado de matemática e, além disso, ele deve conter reflexões sobre os materiais escolhidos. Diferenciando-se do portfólio de matemática não-digital, no pbworks não tem sido exigido que o estudante justifique suas postagens. Isso favorece a demonstração de um estilo pessoal de identificação, ou seja, além das imagens que já existiam nos portfólios de matemática, pode-se criar gifs e outros recursos dinâmicos. Tal estilo para Lévy (2004) é a apropriação do espaço dinâmico para aprender a matemática e a conhecer a si mesmo.

A interpretação dada pela maioria dos estudantes à diferenciação ou não dos portfólios de matemática e os pbworks já é uma ação de plena responsabilidade sobre seu processo de aprendizagem pois, segundo Freire (1999), além da autonomia para definir cada um para si o que cada instrumento significa, eles não utilizam necessariamente os recursos sugeridos pela professora.

Nessa produção chama a atenção a criatividade dos estudantes na exploração dos recursos digitais. As tecnologias digitais possibilitam que os estudantes utilizem em seus portfólios de matemática online uma diversidade de materiais, estratégias e técnicas que, segundo Papert (1994), apontam para aprendizagens de matemática. Fazem parte desse rol de materiais, estratégias e técnicas, edições complexas, contextos e ações dos estudantes de forma a cooperar um com o outros, além de explicações sobre como resolvem suas "contas" de forma que outra pessoa lendo compreende o seu processo de aprendizagem. De acordo com Ribeiro (2003), tais estratégias podem ser caracterizadas como metacognitivas.

O tema central do portfólio de matemática é a avaliação, mas em conseqüência da contextualização dada à matemática via uso de tecnologias digitais, segundo Bona e Basso (2009b), este é o foco de pesquisa agora, ou seja, qual o recurso tecnológico digital que viabilizaria ainda mais a necessidade de se aprender a matemática da escola? Considerando que os recursos tecnológicos digitais são incorporados pelos estudantes de forma natural na construção do portfólio de matemática e que ambos, portfólio e 
recursos digitais, encontram-se muitas vezes amalgamados, os estudantes interpretam o portfólio como parte do recurso digital. No entanto, a avaliação permanece presente e precisa acompanhar o trabalho cada vez mais dinâmico das aulas. Os instrumentos de avaliação, incluindo a leitura do professor sobre o processo de aprendizagem de cada estudante, estão em permanentemente construção e mudança. Mas se todo esse processo encontra-se em permanente transformação, porque persiste em muitas escolas, a estratégia de, para avaliar os estudantes, utilizar apenas uma prova objetiva? (Freire (1996), Lévy (2004) e Perreunoud (1999). A prova deve existir de forma a ser mais uma avaliação, mas não o centro da avaliação, já que a avaliação é um componente da pratica docente e essencial a todo o ser humano para seu próprio crescimento, segundo Hadji (1994).

\section{Material e Métodos}

Os portfólios de matemática construídos no pbworks ou apenas postados nele são escritos, e/ou estão na forma de hipertexto, pois a escrita é linear e obedece a certa seqüência na sua construção, enquanto que o hipertexto é uma tecnologia mais complexa, não linear e inalterável, segundo Bairral e Power (2006), que permite organizar uma base de informação em "partes" que estão conectados por uma relação, que acessam de diferentes formas a mesma informação, sendo assim uma rede. Ou seja, por meio de links e novas páginas criadas num mesmo espaço denominado pbworks são dispostas muitas atividades correlacionadas e que por diversas formas e caminhos verifico um conceito de matemática, por exemplo, de área de uma figura plana, com exemplos concretos, abstratos, simples do caderno scanneado, ou de print screen de um programa e/ou objeto de aprendizagem, onde toda a rede tem a finalidade de demonstrar a aprendizagem de a matemática, ficando assim mais lógico e acessível à compreensão dos conceitos de matemática. Entendendo a matemática como uma ciência de construção histórica e social, que surge e se constitui, permanentemente, a partir das necessidades e interesses do homem. E assim, é uma atividade inerente ao ser humano, porque só ele é capaz de modelar situações, utilizar técnicas diversas em busca de determinados resultados. Esta rede de idas e vindas por diferentes caminhos em torno de um mesmo conceito de matemática proporciona ao estudante uma construção de significado de acordo com seus pré-requisitos e respeitando seu tempo e espaço de aprendizagem.

O texto e o hipertexto são componentes "rodeados" de estratégias metacognitivas. Os consideramos como elementos fundamentais para a compreensão do processo de aprendizagem do estudante, tanto aos olhos do estudante quanto aos olhos do professor. O portfólio de matemática aos estudantes tem uma ação ainda mais seletiva que o pbworks, na medida em que o pbworks é um conjunto maior de ações do que o portfólio de matemática. Para Chaves (2000) o portfólio é, simultaneamente, uma estratégia que facilita a aprendizagem e permite a avaliação da mesma, mas o portfólio em si não é o foco, mas sim o que o estudante aprendeu ao produzi-lo, sob os olhos da avaliação reflexiva cada vez mais incorporada da tecnologia digital.

A capacidade de autorregular sua própria aprendizagem está relacionada ao grau pelo quais os seres são metacognitivo, motivacional e comportamentalmente participantes ativos em seu próprio processo de aprendizagem. Segundo Vygotsky (1998), há relação direta entre a consciência dos próprios processos cognitivos e a capacidade de controlálos. Esta capacidade de autorregular é ativada pela interação dos estudantes nos pbworks, pois, ao receber um elogio ou uma crítica, o estudante costuma verificar o que fez, reformulando ou reiterando o que ali construiu. Com isso, regula a si mesmo de acordo com o seu conhecimento de matemática. 
Chamamos a atenção para o fato que, com os hipertextos, a linguagem simbólica da matemática não é o essencial, mesmo estando presente nas resoluções dos estudantes. Consideramos que as explicações dos estudantes sobre como se resolve é que são essenciais para a compreensão do professor sobre a aprendizagem do estudante. Elas se apresentam para o professor como recursos importantes, tanto para a avaliação do estudante quanto para criar formas de suprir as dificuldades dos estudantes ali apontadas. Como cita D’Ambrosio (1996, p.58), “ Não que se tenha relaxado o rigor, mas,sem dúvida, o rigor científico hoje é de outra natureza”, porque o homem de hoje não é o mesmo e ontem, deixando claro que os meios de observação, de coleção de dados e de processamentos desses dados, que são essenciais na criação matemática, mudaram profundamente.

De acordo com as edições dos pbworks e destes, uma seleção ao portfólio de matemática, observa-se as possibilidades e necessidades dos estudantes ao se apropriarem dos recursos das tecnologias digitais, de forma natural, segundo Basso (2009), pois faz parte do seu contexto; com estas buscam superar dificuldades melhorando o seu aprendizado e tornando a matemática "viva" em tudo o que faz, como por exemplo, os trabalhos de biologia que foram transformados em blogs com links no pbworks. Tais edições são aprendidas pelos estudantes a ponto deles publicarem tutoriais nos pbworks com os procedimentos para elaborar trabalhos, e no portfólio de matemática o mesmo é apontado com um viés de qual a matemática se faz ali presente.

A formação intelectual está ligada ao desenvolvimento afetivo e metacognitivo, e evidentemente ao cognitivo, segundo Saint-Pierre e Lafortune (1996), sendo os conhecimentos metacognitivos aqueles relacionados com a cognição.

Para Piaget, a inteligência depende da ação do sujeito sobre os objetos, numa espécie de diálogo entre estruturas internas e a realidade externa, isto é, "as estruturas operativas não resultam de aprendizagem nem de programa hereditário inato: assim não podem nascer senão de uma construção". Esta ideia do Piaget sobre inteligência integra-se a ideia de Gardner (1994), pois este defende a que cada pessoa é proprietária de diferentes inteligências, organizadas no cérebro humano, onde, por exemplo, qualquer conteúdo, de qualquer disciplina escolar em todos os níveis de escolaridade, permite a exploração de atividade em que os estudantes manifestem suas inteligências. Logo, a ação do professor de mobilizar os estudantes através de atividades que despertem as inteligências de cada um aos objetos da matemática é fundamental; o diálogo entre a aula e os pré-requisitos do estudante é que irão proporcionar a compreensão de um novo conteúdo, por exemplo. Tal ideia de inteligência é vivenciada pelos estudantes em seus portfólios de matemática no pbworks.

Nessa prática docente busca-se o que Piaget (1976) denomina como educar e que constitui em provocar a atividade, ou seja, estimular a procura do conhecimento. Nesse sentido, o professor não deve pensar no que a criança é, mas no que ela pode se tornar. Educar crianças não se refere tanto a transmissão de conteúdos - dado que o conhecimento não é uma cópia - mas sim, favorecer a atividade mental do estudante, possibilitando que o professor crie espaços em sala de aula favoráveis. Consideramos que o conhecimento é também como uma relação entre objeto e sujeito. Esta relação está cada vez mais dinâmica e a internet é um espaço onde estão os pbworks, e com isso se está construindo uma rede de aprender matemática sob um enfoque de aprender entre todos, que a cada dia é postada uma nova ação do estudante.

O método essencial de trabalho é o diálogo, a interação e a cooperação entre todos, tanto o professor com a matemática e os estudantes com as tecnologias, onde estes três elementos primam pelo sucesso do trabalho como um todo. 


\section{Coleta de dados}

O trabalho foi desenvolvido com uma metodologia de pesquisa-ação com 25 estudantes do $3^{\circ}$ ano do Ensino Médio de uma escola pública estadual de Porto Alegre. Devido ao fato dos estudantes serem nativos digitais, esses auxiliam a professora no uso da tecnologia, Já a professora-pesquisadora, desperta o interesse dos estudantes pelo estudo da matemática sendo que $95 \%$ da comunicação é prioritariamente online e extraclasse. A atividade é extraclasse com a intenção também de despertar o gosto de aprender, além do hábito de estudar, não apenas na escola.

Esta pesquisa-ação é uma continuidade da pesquisa iniciada em 2009, especificamente sobre os portfólios de matemática. Como escrito anteriormente, a pesquisa é dinâmica e possibilita que os estudantes participem da escola ativamente, estabelece um nível de exigência maior por parte da professora no sentido de fazer com que objetivo de ter os estudantes em aula de forma ativa e aprendendo a aprender matemática, seja mantido permanentemente. Para além dos demais resultados apresentados nesse artigo, essa exigência em relação à prática docente da professora, também se constitui em um resultado do trabalho com portfólios de matemática.

A escolha dos dados são extratos de diversos trabalhos online dos estudantes postados em seus pbworks, estando ou não selecionados em seus portfólios de matemática, pois estes são coletados três vezes no ano, sendo apenas no $1^{\circ}$ e $2^{\circ}$ trimestre obrigatórios. Os extratos apresentados nesse artigo, todos disponíveis para acesso online, são print screen da área de trabalho dos estudantes e constituem-se em amostras do que é um portfólio de matemática em um pbworks ou vice-versa, da apropriação tecnológica digital e da interação e/ou cooperação entre os estudantes para aprender matemática. Além disso, este artigo tem a intenção também de evidenciar uma prática docente que sempre necessita ser reformulada a cada ano e turma, mantendo elementos de sucesso e outros sendo agregados para cada vez mais trazer os estudantes para as aulas de matemática de forma ativa. Espera-se que tais escolhas ofereçam elementos que permitam analisar as fraquezas e potencialidades da proposta, assim como despertar o interesse em usar as tecnologias digitais. Espera-se também despertar o interesse do uso dos portfólios de matemática como uma forma de possibilitar um espaço extraclasse para os estudantes aprenderem a estudar e aprenderem matemática. A leitura dos portfólios de matemática e/ou pbworks é realizada via um modelo de avaliação contendo categorias e indicadores (Bona e Basso, 2010). Tal leitura possibilita a análise de conteúdo, segundo Bardin (1977, p.29), que enriquece o trabalho exploratório, pois propicia a descoberta e faz a prova pela confirmação ou refutação de verdades provisórias.

\section{Resultados Parciais e Perspectivas}

Atualmente a pesquisa sobre os portfólios de matemática está em fase final e este artigo é uma consequiência deste trabalho. Pretende-se dar continuidade a esse estudo a partir de ideias como: Pbworks, com seu formato hipertextual, agregados aos portfólios de matemática, despertam o interesse dos estudantes em aprender matemática?

Os recortes dos portfólios abaixo não serão do mesmo estudante para destacar a diversidade e o não controle do professor sobre o uso dos recursos tecnológicos e suas associações com a disciplina de matemática, sendo todos evidências que sustentam a proposta dessa pesquisa. Os extratos dos pbworks que não estão presentes nos portfólios de matemática são para demonstrar a leitura feita pelo estudante sobre a diferenciação ou não dos instrumentos: portfólio de matemática e pbworks - cadernos de matemática online como os estudantes o denominam.

Inicialmente cabe ressaltar que nesta turma todos os estudantes mantêm seus pbworks atualizados e postam atividades solicitadas, criam outras atividades que se relacionam 
com a matemática, e algumas atividades realizadas em aula são postadas no pbworks por livre escolha dos estudantes, como pode ser verificado no espaço da professora: http://matematicalegre.pbworks.com, no qual estão listados todos os links dos pbworks individuais da turma.

Dos 25 estudantes, todos entregaram o seu portfólio de matemática via pbworks, anexado ou em página linkada no front page desse ambiente virtual. Também cabe ressaltar que na turma há uma estudante de inclusão que apresenta necessidades especiais de aprendizagem e que conta com o apoio dos colegas para a realização das atividades, incluindo a postagem no pbworks. Destaco que os nomes dos estudantes estão mantidos com a autorização destes e de seus responsáveis e também pelo fato que esses mesmo estudantes têm apresentado seus trabalhos em outros eventos.

Primeiramente aponta-se o aspecto de interação entre os estudantes e seus diferentes estilos de identificação pessoal, como seguem extratos abaixo:
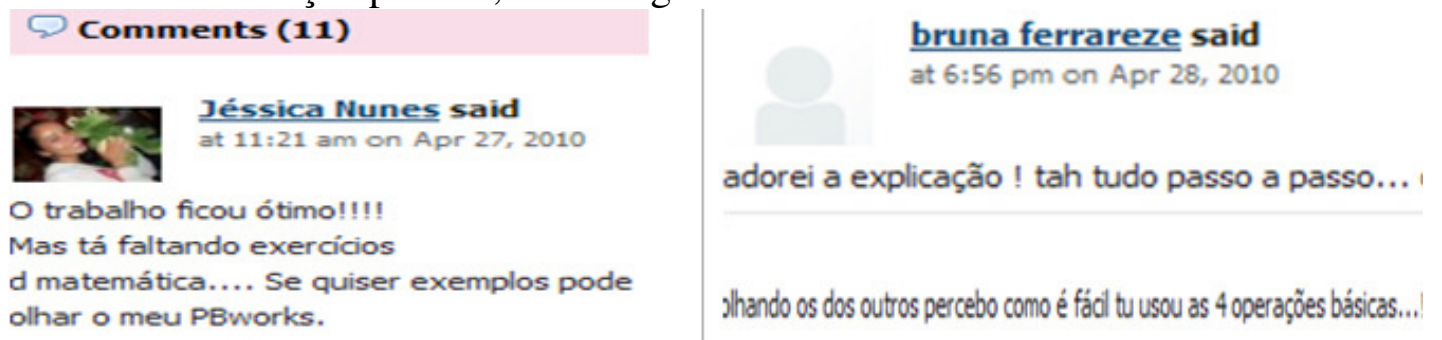

Extrato 1 - Recorte dos comentários do pbworks da estudante Greyce referente ao $1^{\circ}$ trimestre.

O extrato 1 aponta a estudante Jéssica querendo ajudar a Greyce, e a Bruna observa que a forma como a Greyce resolve é tão fácil como as operações básicas. Já na imagem 2 novamente é evidente a boa explicação da colega, ou seja, este é um aspecto metacognitivo importante, pois a estudante Greyce descreve seu modo de resolver de forma clara que os colegas entendem. Ainda, no comentário do Andrius existe uma constatação de que a caixa construída pela estudante de forma concreta está muito parecida com a representada no pbworks.

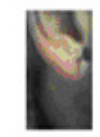

Greyce *.* Muito boa a explicação!

E a caixinha colorida qee tu desenhou ficom parecida com a tua :D Bejos; ; ${ }^{* 8}$

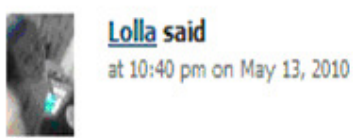

nossa colega ta muito bom teu pbworks, eu gostei do exercicio :

bejos Grayce

Sara Caroline Schenato Leite said

at 10:00 pm on May 2, 2010

Greyce, adoro o teu PBworks, dei uma coladinha no teu pra fazer aqueles trabahinhos das caixinhas hehehehe mas não da nada. Continua assim, que ta bem legal o teu PB. beeejãa Sara!!!

Extrato 2 - Outro recorte dos comentários do pbworks da estudante Greyce - $1^{\circ}$ trimestre.

O comentário da Sara tem um aspecto de incentivo, mas a ideia da "coladinha" foi questionada, e a mesma argumentou que essa era uma forma de expressar que usaria a mesma ideia de planificar os sólidos para depois calcular a área. Esta estudante quando questionada pela professora ficou braba, pois disse: "a sora não entende meu jeito, era só olhar o meu trabalho que ia ver que não copiei, bah". Outros aspectos interessantes nesses dois extratos são: 1. a afetividade dos estudantes entre si, sendo esta uma evidência de que o ambiente de sala de aula é saudável e que há boa comunicação entre os estudantes; 2 . os dias/horários de postagens que são à noite e/ou nos finais de semana. 
Ainda no que tange a interação entre os estudantes, apontamos o extrato 3 do portfólio de matemática do $2^{\circ}$ trimestre da estudante Vanessa, na qual ela escolheu criar um item em seu portfólio de matemática sobre os exercícios das colegas postados no pbworks.

2- Es te exercício es colhi do PBworks da Bruna.

Deveria calc ular a áre a de uma pirâmide quadrangular regular. Nes te exercício, haviam dois dados, o valor da ares ta da base $\epsilon$ - apótema da pirâmide. Primeiro des cobria a área da bos e, que é quadrangular, por is so utilizei a fómula lado.lado. Depois a área lateral, que fiz a bose multiplicada pela latera também multiplicado pelos 4 lados da pirâmide, o res ultado dividido por 2. Somando os dois res ultados, encontro a área total.

3- Es te, es colhi do Pbworks da Débora.

Prec is ava des cobrir o valor de 10000 c aixas de s abão com os valores da figura.

Para is s o, prec is ei calc ular a área total: c hão/tampa, laterais , frente/ fundo, por fim s omar todos os valores, encontrar a área total e depois foi só multiplicar pe la quantidade de caixas des ejados $(10000)$.

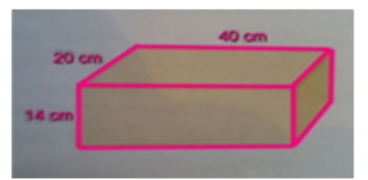

Extrato 3 - Exercícios apontados no portfólio de matemática do $2^{\circ}$ trimestre da Vanessa.

O extrato 4 é uma demonstração de que todo seu humano tem certa resistência ao novo, ou seja, a estudante Jaqueline adora tecnologia digital, mas a novidade do pbworks assustou e ainda mais em inglês, mas logo mudou de opinião. Além disso, a estudante achou uma forma de solucionar o seu problema de não ter internet em casa, que inclusive é o mesmo da professora e de mais de $80 \%$ do corpo discente da escola. Tal item faz parte do seu portfólio de matemática, então novamente o pbworks é entendido como uma atividade que pode ou não ser selecionado no portfólio de matemática, constituindo-se o pbworks, portanto, em um caderno online.

\section{PBWOKS}

Todo ano, quando a professora Aline entra na sala para dar a primeira aula ela surge com uma novidade. Neste ano não foi diferente. Dessa vez ela veio com a ideia do pbworks, uma espécie de blog para podemos divulgar na rede os nossos trabalhos e projetos. Cada aluno teve que criar o seu e fazer os exercícios solicitados pela professora,

No começo, a ideia não me agradou muito. Em primeiro lugar porque o site é em inglês (e eu não sei bulhufas de inglês). Segundo porque como eu trabalho e não tenho computador em casa dependo da disponibilidade de horário do laboratório e dos dias da minha folga. Tanto que não cumpri todas as atividades pois não tive tempo. Tudo bem que eu posso ir na lan house mas eu trabalho o dia todo e também nos fins de semana.

Mas, agora eu até já me acostumei com o pb, acho que é uma excelente ferramenta para a nossa aprendizagem e também temos a oportunidade de mostrar os nossos trabalhos pra quem quiser ver. Outro ponto positivo do pb é que fica mais fácil de fazer atividades interdisciplinares, como a do filme Alice no País das Maravilhas que foi elaborada pelas professoras Aline de Matemática e Ivalcir de Literatura.

Extrato 4 - Item do portfólio de matemática do $1^{\circ}$ trimestre da Jaqueline

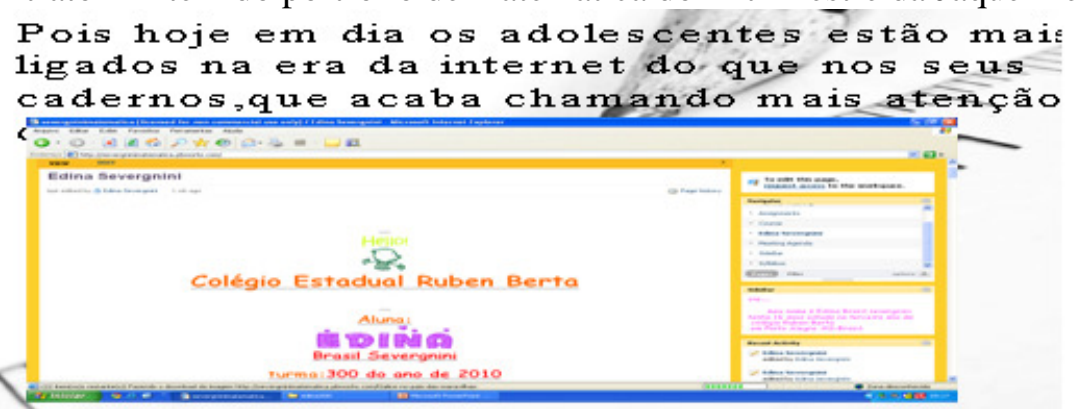


Extrato 5 - Portfólio de matemática do $1^{\circ}$ trimestre da Edina

O extrato 5 é mais uma demonstração da alegria possibilitada aos estudantes de aprender matemática de forma dinâmica e via recursos tecnológicos digitais, assim também como a diversão de usar o applets do Gira - Gira, em que os estudantes não de deram por vencidos ate descobrir como construir corpos arredondados regulares, como mostrada a experimentação no extrato 6 .

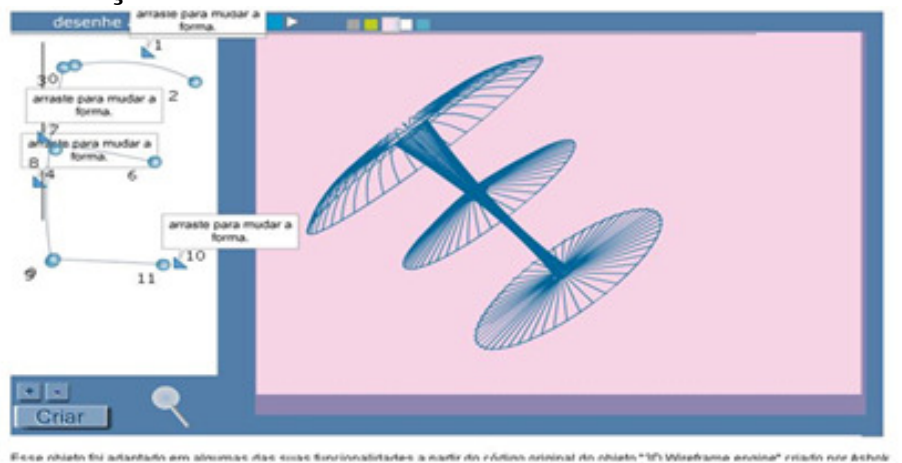

Adorei ESSA atividade pois mexe com nossa imaginação; Por exemplo eu fui Fazer a Um 'e' a letra do Nome meu, e Ficou de UM jeito bem ": louco": .

Extrato 6 - Recorte do pbworks da Edina sobre o applets Gira-Gira.
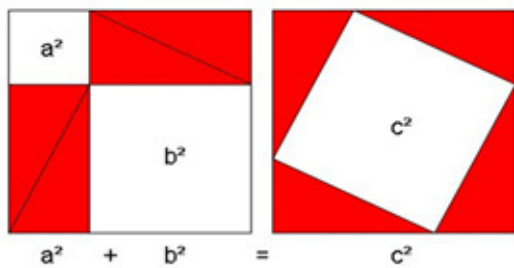

Esse é o famoso "Tio Pit"

Extrato 7 - Pbworks da Gabriele no $1^{\circ}$ trimestre: matemática alegre

O extrato 7 é uma demonstração da estudante de que a matemática pode ser alegre inclusive com um conteúdo que é de ensino fundamental, mas os objetos de aprendizagem pesquisados como de revisão de conceitos de geometria plana e outros encantou os estudantes, como o do Teorema de Pitágoras estar relacionado com as áreas, e o applets sobre frações no extrato 8.

Esse site é em espanhol, onde primeiro a gente baixa um aplicativo executável e depois através dele pode brincar com os joguinhos como esse de frações:

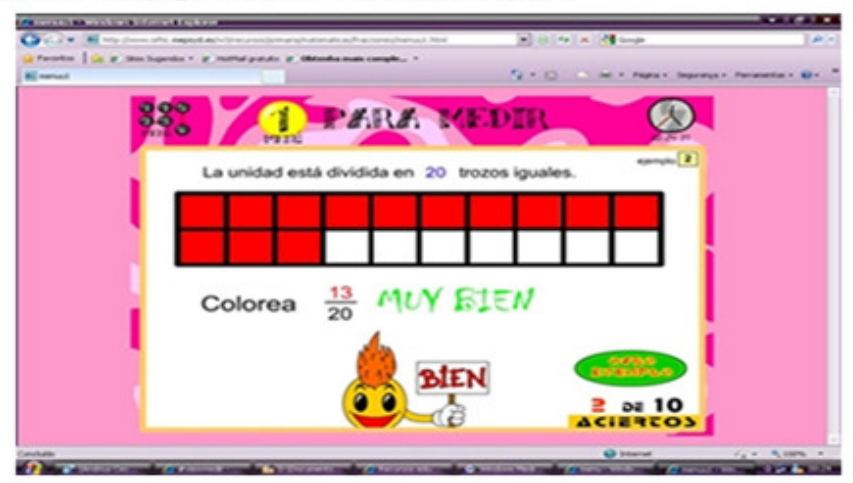

Extrato 8 - Encantamento da estudante Débora com o applets sobre Frações.

Observamos que a estudante, em pleno $3^{\circ}$ ano do ensino médio, tem dificuldades em compreender frações. Em função da necessidade de realizar os exercícios de geometria plana e diante da possibilidade de aprender esse conceito e operar com as frações, a experimentação e o uso de recursos digitais de maneira que ela mesma pudesse entender e achar uma lógica nas soluções propostas foi importante ao seu processo de aprendizagem, tanto em termos de responsabilidade quanto em autonomia. A estudante 
foi questionada no sentido de porque ainda não tentou aprender este assunto denominado frações e sua resposta foi: "Sora apenas na $5^{\text {a }}$ série vi isso, depois os professores deixavam usar calculadora ou davam os exercício na forma de efetue, onde não precisava pensar no que é $5 / 4$ de $16 \mathrm{~cm}$ de altura, entende? E a Senhora deixa usar o pc, mas tem de saber explicar, então tem de aprender,ne?"

A preocupação dos estudantes em relação à comunicação e compreensão dos trabalhos criados, também pode ser observada como destacado nos extratos 9 e 10 a seguir.

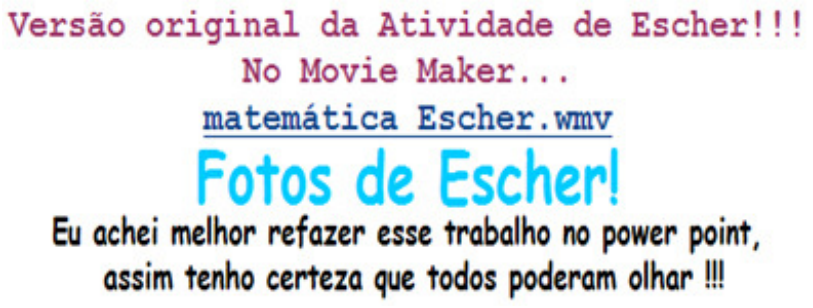

Extrato 9 - Print Screen do pbworks da estudante Greyce

O extrato 9 é demonstração da preocupação da estudante de que todos os seus colegas visualizem sua atividade e para isso ela o construiu em duas versões. Além disso, após a colega Débora elaborar um tutorial sobre como usar o Movie Maker, - que pode ser acessado pelo link http://www.youtube.com/watch? $\mathrm{v}=\mathrm{BHnhjD4j9ks} \mathrm{-} \mathrm{ela} \mathrm{sentiu-se} \mathrm{na}$ obrigação de fazer uma apresentação mais adequada do que no ppt. Ainda não satisfeita, usou o orkut para avisar a professora da sua preocupação, como aponta o extrato 10.

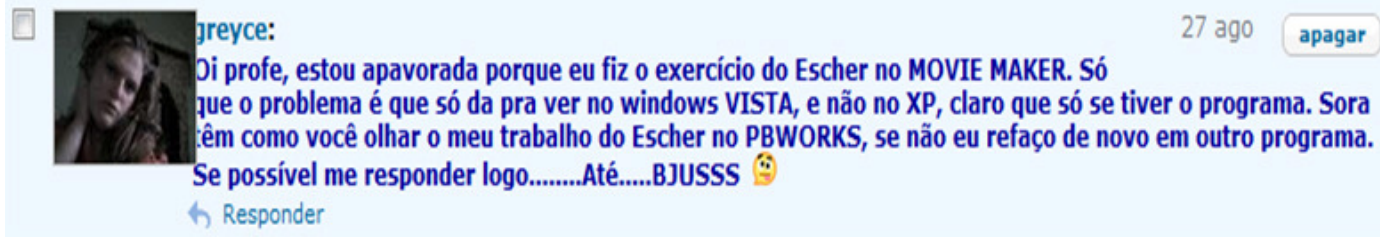

Extrato 10 - Recorte do orkut da professora de matemática.

O extrato 11 contém a comunicação da estudante com a professora, ou melhor, a conversa no "meio do portfólio de matemática do $1^{\circ}$ trimestre" sobre onde a mesma visualiza a matemática.

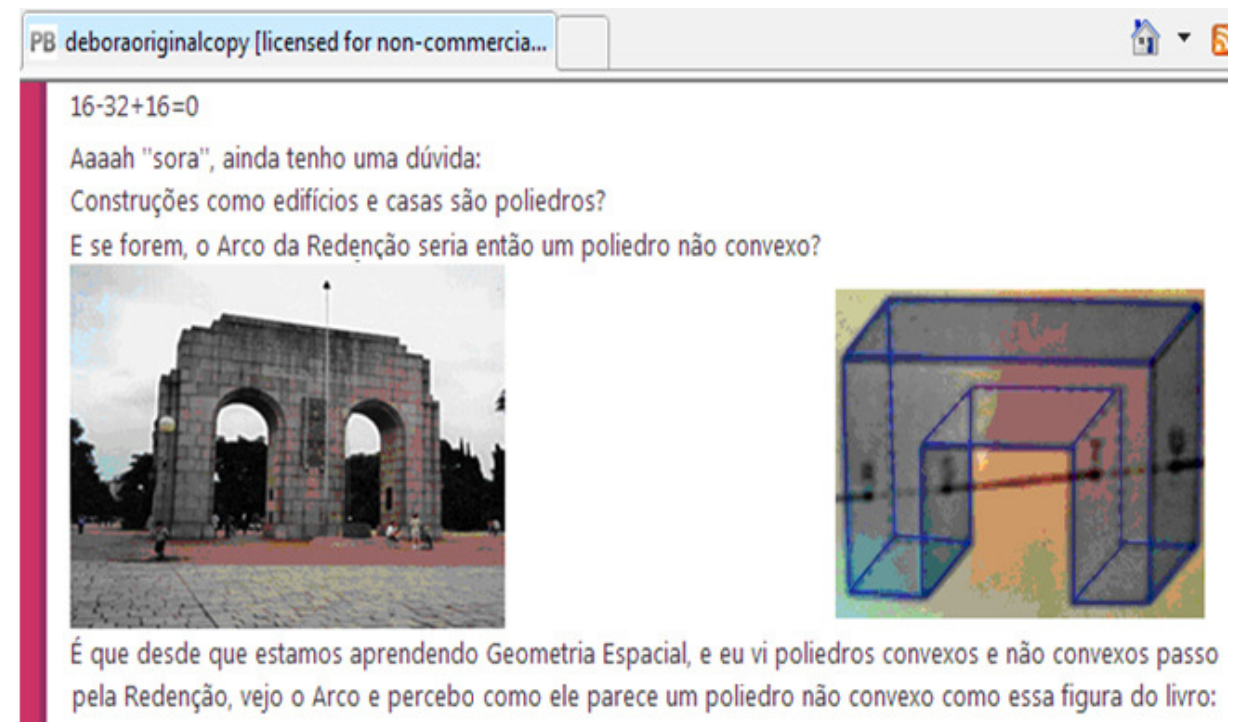

Extrato 11 - Recorte do portfólio de matemática postado em página individual no pbworks com muitos hiperlinks compondo um hipertexto.

De um universo extenso - e encantador - de materiais produzidos por estudantes ao assumirem seu processo de aprendizagem, tivemos que optar por uns poucos. Outros trabalhos poderão ser gerados a partir dos materiais criados pelos estudantes em seus

V. $8 \mathrm{~N}^{\mathrm{o}} 3$, dezembro, 2010 
pbworks o que nos permitirá compartilhar outros resultados da pesquisa-ação empreendida nesse estudo e discutir possibilidades de mudanças nas práticas docentes.

5. Considerações Finais

O trabalho com os portfólios de matemática está a cada ano melhor, cada vez mais parte da vida escolar dos estudantes da escola básica, de uma forma a tornar a matemática necessária a vida dos mesmos através dos recursos tecnológicos digitais, que tanto só encanta, e de um dinamismo inevitável atualmente. E a pratica docente da professora é mais eficiente e eficaz com o sucesso dos estudantes não só em notas, mas na sua avaliação pessoal como um todo.

Não há maior alegria do que ver o sorriso de um estudante emocionado com os olhos brilhando para o computador e diz: "Sora, eu entendi um pouquinho de matemática". E a valorização de si mesmo a cada trabalho realizado e compartilhado com a professora, colegas, e com o mundo da internet.

\section{Referências}

BAIRRAL, M.; POWER,A., A escrita e o pensamento matemático: Interações e potencialidade. Campinas, São Paulo: Papirus, 2006.

BARDIN, L. Análise de conteúdo. Lisboa: Edições 70, Ltda, 1977.

BASSO, M.V.A. Palestra Matemática na Escola: Experiências e Perspectivas. Mesa Redonda Ciência - Formação aos professores da Rede Municipal de Ensino de Porto Alegre. <http://euler.mat.ufrgs.br/ mbasso/expmat_SMED2009.pdf> Acesso: 9setembro/2009. BONA, A.S.; BASSO, M. V. A. O Portfólio de Matemática: um instrumento de avaliação reflexiva e também uma estratégia de aprendizado. In: Anais do XIII EBRAPEM, Goiânia. Setembro de 2009. Disponível em: http://vivaexatas.pbworks.com em gt11_bona_ta.pdf ou http://www.ebrapem.mat.br/ em gt11 e a3. Acesso: 8 agosto/2010b.

BONA, A.S; BASSO, M.V.A. Portfólio de Matemática: um instrumento de análise do processo de aprendizagem. In: RENOTE - Revista Novas Tecnologias na Educação. XIV Ciclo de Palestras Novas Tecnologias na Educação. Vol. $7 \mathrm{~N}^{\mathbf{0}} 2$. Dezembro 2009.2 Disponível: http://www.cinted.ufrgs.br/renote/dez2009/artigos/10a_alinesilva.pdf. Acesso: 7maio/2010a.

CHAVES, I. Sá. Portfólios Reflexivos: estratégias de formação e de supervisão. Aveiro: Universidade, 2000.

D’AMBROSIO, U. Educação Matemática: da teoria à práxis. Campinas, São Paulo: Papirus, 1996.

FREIRE, P. Pedagogia da Autonomia: saberes necessários à prática educativa. São Paulo: Paz e Terra, 1996.

FREIRE, P. Educação com Prática de Liberdade. São Paulo: Paz e Terra, 1999.

GARDNER, H. Inteligências Múltiplas. A teoria na prática. Porto Alegre, Artmed, 1995.

HADJI, C. A avaliação, regras do jogo: Das intenções aos instrumentos. Porto: Porto Ed.,1994.

LAFORTUNE, L., SAINT-PIERRE, L., A afetividade e a metacognição na sala de aula. Lisboa: Instituto Piaget, 1996.

LÉVY, P. As tecnologias da Inteligência - O futuro do pensamento na era da informática. 13 $3^{\mathrm{a}}$ ed. São Paulo: Editora 34, 2004.

PAPERT,S. A Máquina das crianças. Porto Alegre: Artmed, 1994.

PERRENOUD, P. Avaliação: da excelência à regulação das aprendizagens - entre duas lógicas. Porto Alegre: Artmed, 1999.

PIAGET, J. Seis estudos de Psicologia. Rio de Janeiro: Forense, 1976. 
RIBEIRO, C. Metacognição: um apoio ao processo de aprendizagem. São Paulo: Psicologia, Reflexão e Crítica, 2003.

VYGOTSKY, L. S. Formação Social da Mente. São Paulo, Martins Fontes, 1998. 